$\mathbf{2 7}(2), 185-195$

\title{
New Method for Preference Measurement in Ranking-based Conjoint Analysis
}

\author{
$\mathrm{Bu}$-Yong $\operatorname{Kim}^{a, 1}$ \\ ${ }^{a}$ Department of Statistics, Sookmyung Women's University \\ (Received October 20, 2013; Revised December 2, 2013; Accepted December 2, 2013)
}

\begin{abstract}
Ranking-based conjoint analysis is widely used in various fields such as marketing research. While the ranking-based conjoint affords several advantages over the rating-based or choice-based conjoint, it has a serious shortcoming that respondents have much difficulty in ranking the product profiles in order of preference when many profiles are involved. This article suggests a new method for the preference measurement to improve the response efficiency. The method employs the concept of ranking sets that let the respondent evaluate a small number of profiles at a time. Through the proposed method, preference rankings of profiles obtained from each ranking set are aggregated to generate overall rankings. The balanced incomplete block design is expanded and transformed to the dual design in order to construct well-balanced ranking sets that can accommodate a large number of profiles. The proposed method is applied to the analysis of consumer preferences for perfume-for-women.
\end{abstract}

Keywords: Ranking-based conjoint, ranking set, balanced incomplete block design, perfume-for-women.

\section{1. 서론}

마케팅조사 분야에서 발전해 온 컨조인트분석은 다양한 학문 및 산업에서 광범위하게 활용되고 있다. 이 분석기법은 제품(서비스, 전략, 정책, 디자인, 프로그램 등도 포함됨)의 주요 속성과 수준들에 요인설 계를 적용하여 프로파일들을 구성하고 각 프로파일에 대한 소비자들의 선호도를 측정하여, 수준별 부분 가치를 추정하고 속성들의 상대적 중요도를 평가하는데 사용된다. 컨조인트분석 결과는 소비자 선호도 분석, 구매행동분석, 신제품개발, 시장점유율 예측, 시장세분화, 제품특성의 최적화, 판매가격 결정, 포 지셔닝과 판매촉진 등에 활용되고 있다.

컨조인트분석은 선호도 측정이나 부분가치 추정을 위해 채택된 방법에 따라 몇 가지 기법으로 분류된다. 선호도 측정방법에 따른 자료의 유형을 기준으로 등급기반, 순위기반, 선택기반 컨조인트분석으로 분류 되는데, 각 기법들은 상이한 특성과 장단점을 가지고 있다. 등급기반 컨조인트분석에서는 응답자가 프 로파일들에 대한 선호도 평가를 비교적 웝게 할 수 있고, 부분가치 추정을 위하여 최소자승추정법을 적 용할 수 있다는 장점을 가지고 있다. 그러나 선호도 평가과정에서 응답자들이 프로파일들에 대해 충분 한 변별력을 갖기 어렵기 때문에 측정된 자료의 품질이 낮다는 심각한 단점을 가지고 있다. 반면에 순위

\footnotetext{
${ }^{1}$ Department of Statistics, Sookmyung Women's University, 100 Cheongpa-ro 47-gil, Yongsan-gu, Seoul 140-742, Korea. E-mail: buykim@sookmyung.ac.kr
} 
기반 컨조인트분석에서는 응답자가 프로파일들에 대한 선호도를 변별력을 가지고 평가할 수 있다는 장 점을 가지고 있다. Sayadi 등 (2005)은 순위에 의한 선호도 측정이 등급에 의한 측정보다 제품 간의 차 이를 잘 반영한다고 하였다. 그러나 다수의 프로파일에 대해 선호도 순위를 매기는 작업이 응답자에게 큰 부담이 되고 정확한 평가가 이루어지기 어렵다는 단점을 가지고 있다. 선택기반 컨조인트분석에서는 소비자의 실제 구매행동과 매우 유사한 상황에서 현실적인 선호도 평가가 실행된다는 장점을 가지고 있 으나, 부분가치 추정과정이 비교적 복잡하다는 단점을 가지고 있다. 한편, 등급기반과 순위기반 컨조인 트분석에서는 각 응답자별로 분석한 결과를 전체로 종합하기 때문에 개인별 부분가치에 바탕을 둔 시장 세분화 작업을 할 수 있지만, 선택기반 컨조인트분석에서는 응답자 전체를 통합한 자료에 대하여 분석 을 하기 때문에 시장세분화 작업이 불가능하다. 이러한 장단점과 특성들이 고려되어 순위기반 컨조인트 분석(ranking-based conjoint analysis; $\mathrm{RBCA}$ )이 다양한 산업분야(제조, 디자인, 정보보안, 여행, 관 광, 요식, 식품, 의료, 보건행정, 교통, 의류 등)에서 널리 사용되고 있다. $\mathrm{RBCA}$ 를 적용한 사례연구로 는 Min 등 (2000), Shin 등 (2004), Lee 등 (2004), Kim (2005), Kim 등 (2005), Lee 등 (2005), Choi (2006), Kim과 Park (2007), Shin 등 (2007), Park 등 (2008), Yoon과 Cho (2009), Lee 등 (2010), Jo (2010), Chen 등 (2010), Jin 등 (2010), Ong 등 (2010), Park과 Lee (2011), Jung (2012), Choi 등 (2012), Hong 등 (2012)이 있다.

본 논문에서는 $\mathrm{RBCA}$ 를 위한 선호도 순위를 효율적으로 측정할 수 있는 방법에 관하여 연구한다. $\mathrm{RBCA}$ 의 초기 단계에서는 분석대상 제품의 속성과 수준들을 파악하고, 요인설계에 의해 제품프로파일 들을 구성하여 응답자들에게 제시하고 선호도 순위를 측정하는 작업을 한다. 선호도 순위를 측정하기 위한 기존의 방법들이 몇 가지 있지만, 그 방법들은 응답자에게 과중한 부담과 피곤을 느끼게 하고, 응 답자가 비교해야 할 프로파일 짝의 개수가 지나치게 많아서 평가에 과도한 시간이 요구되고, 조사지를 사용하는 선호도 측정에서는 채택하기 곤란하고, 응답자가 선호도를 정확하게 평가하기 어렵다는 단점 들을 가지고 있다. 따라서 기존의 선호도 측정방법을 개선하기 위하여 순위집합 개념을 제안한다. 즉, 응답자가 순위를 매기기에 어렵지 않을 정도로 소수의 프로파일들을 순위집합으로 묶되, 프로파일 전체 의 순위를 결정하는데 충분한 개수의 순위집합들을 구성하여 응답자에게 제시하는 방법이다. 순위집합 을 체계적으로 구성하기 위하여, 균형불완비블록설계(balanced incomplete block design; BIBD)를 두 배 또는 세 배 확장하고 쌍체설계로 전환하여 순위집합을 구성하는 방법을 제시한다. 그리고 제안된 선 호도 측정방법을 실제로 적용하여 여성용 향수제품에 대한 소비자 선호도분석을 실행하고자 한다.

\section{2. 순위집합을 이용한 선호도 측정방법}

\section{1. 순위집합 개념의 도입}

$\mathrm{RBCA}$ 에서 선호도 측정을 위한 조사를 설계할 때 중요시해야 할 사항은 통계적 효율성과 응답효율성인 데, 통계적 효율성에 관한 연구는 이미 많이 이루어졌기 때문에 본 연구에서는 응답효율성에 초점을 맞 춘다. 프로파일들에 대한 선호도 순위를 측정하는 기존의 방법들은 다음과 같다. (1) 응답자에게 분석대 상 프로파일 전체를 동시에 제시하고 각 프로파일들에 대한 선호도를 순위로 응답하게 하는 방법이다. 제 1 장에 소개한 사례연구들의 대부분은 이 측정방법을 채택하고 있다. 그런데 요인설계에 의해 구성된 프로파일의 개수는 상당히 많은 경우가 대부분이고, 부분요인설계법에 따라 프로파일의 일부를 선정하 더라도 일정 수준의 통계적 효율성을 유지하기 위해서 상당히 많은 개수의 프로파일을 포함시키는 것이 불가피하다. 이러한 상황에서 전체 프로파일에 대한 선호도를 순위로 평가하게 하면, 응답자는 과중한 부담을 느끼고 선호도를 정확하게 평가하기 어렵다. (2) 전체 프로파일을 두 개씩의 모든 가능한 짝으로 묶어서 응답자에게 제시하고 각 짝에서 선호하는 프로파일을 선택하거나 프로파일에 대한 상대적인 선 
Table 2.1. Ranking sets constructed by expanding BIBD10 doubly and transforming to dual design

\begin{tabular}{ccccccccccccc}
\hline 순위집합 & 1 & 2 & 3 & 4 & 5 & 6 & 7 & 8 & 9 & 10 & 11 & 12 \\
\hline & 가 & 가 & 가 & 가 & 가 & 다 & 나 & 나 & 나 & 나 & 나 \\
& 다 & 다 & 다 & 다 & 마 & 마 & 라 & 라 & 라 & 라 & 바 & 바 \\
프로파일 & 마 & 마 & 마 & 사 & 사 & 사 & 바 & 바 & 바 & 아 & 아 & 아 \\
& 사 & 사 & 자 & 자 & 자 & 자 & 아 & 아 & 차 & 차 & 차 & 차 \\
& 자 & 카 & 카 & 카 & 카 & 카 & 차 & 타 & 타 & 타 & 타 & 타 \\
\hline
\end{tabular}

호도를 등급으로 응답하게 한 후, 전체 프로파일에 대한 순위로 종합하는 방법이다. 이 방법을 적용하면 선호도 측정을 비교적 정확하게 할 수 있지만, 측정대상 프로파일의 개수가 증가함에 따라 응답자가 비 교해야 할 짝의 개수가 과도하게 많아져서 응답자에게 큰 부담이 되고, 지나친 단순화 경향으로 인해 정 확한 선호도 평가가 이루어질 수 없다는 결점을 가지고 있다. 또한 이 측정방법은 컴퓨터를 사용하는 선 호도 측정에서만 채택 가능하고, 조사지를 사용하는 일반적인 선호도 측정에서는 채택할 수 없다는 한계 를 가지고 있다. (3) 프로파일 전체를 카드로 만들어 응답자에게 제시하고, 선호도에 따라 카드들을 상중 하 세 집락으로 분류하게 하고, 각 집락에 속한 소수의 프로파일들을 대상으로 순위를 매기도록 한 후에 프로파일 전체에 대한 순위로 종합하는 방법이다. 이 측정방법은 $\operatorname{Kim}(2005)$ 에 의해 제안되었는데, 응 답자의 부담을 줄여주면서 선호도 측정을 비교적 정확하게 할 수 있다는 장점을 가지고 있으나 평가 초 기에 이루어진 집락구분에 따라 프로파일들의 순위가 현격하게 영향을 받는다는 한계점이 있다.

따라서 선호도 측정방법의 개선을 통해 응답효율성을 높이기 위하여 순위집합 개념을 도입할 수 있다. 제안된 측정방법에서는 응답자가 선호도 순위를 매기기에 용이하도록 소수의 프로파일들이 포함된 순위 집합들을 구성하며, 통계적 효율성을 고려하여 순위집합의 개수를 적절한 수준으로 결정한다. 응답자들 은 각 순위집합에 속한 프로파일들에 대한 선호도 순위를 응답한다. 응답자가 각 순위집합 내에서 응답 한 순위를 프로파일별 평균으로 변환하여 전체 프로파일에 대한 순위를 결정한다. 이 측정방법을 채택 하면, 기존의 측정방법들을 적용하는 경우에 비하여, 응답자가 프로파일들의 선호도를 순위로 평가하는 작업에 별로 부담을 느끼지 않고 정확한 선호도 순위를 평가할 수 있을 것으로 기대된다.

\section{2. 순위집합의 설계}

제품프로파일의 개수와 순위집합의 개수 및 순위집합들의 크기는 통계적 효율성과 응답효율성을 고려하 여 결정한다. 프로파일들을 각 순위집합에 배치하는 방법으로 우선 임의배치법을 고려할 수 있으나 이 방법에서는 각 프로파일이 전체 순위집합에 동일한 횟수씩 배치된다는 보장을 할 수 없다. 그래서 균형 잡힌 순위집합들을 구성하기 위한 새로운 방법을 제안한다. 가장 간단한 방법은 Kutner 등 (2005)에 수록된 $\mathrm{BIBD}$ 중에서 하나의 설계를 선정하여 블록을 순위집합으로 바꾸고 처리를 프로파일로 교체하 는 방법이다. 예를 들어, BIBD10에 이 방법을 적용하여 순위집합을 구성하면 6 개의 프로파일이 6 개의 순위집합에 각각 5 개씩 배치된다. 그러면 각 프로파일은 특정 순위집합에 한 번만 포함되고, 전체 순위 집합에 5 회씩 동일하게 반복되며, 어느 두 프로파일의 쌍은 4 개의 순위집합에 함께 포함된다는 특징을 갖는다. 그러나 이와 같이 구성한 순위집합에는 프로파일의 개수가 6 개로 제한되어 실제 사례에 적용하 기에 한계가 있다. 왜냐 하면, 실제 상황에서는 평가대상 프로파일의 개수가 상당히 많은 경우가 대부 분이기 때문이다. 따라서 더 많은 프로파일들을 수용할 수 있는 순위집합을 구성하는 방법을 모색해야 한다. $\operatorname{Kim}$ (2012)은 선택기반 컨조인트분석을 위한 선택집합을 구성하기 위하여 BIBD를 두 배로 확 장하고 쌍체설계로 전환시키는 방법을 제시하였다. 이 방법을 $\mathrm{BIBD} 10$ 에 적용하여 구성한 순위집합은 Table 2.1 과 같은데, 채택 가능한 프로파일이 6 개에서 12 개로 증가되며 12 개의 순위집합에 5 개씩의 프 
Table 2.2. Ranking sets constructed by expanding BIBD10 threefold and transforming to dual design

\begin{tabular}{ccccccccccccccccccc}
\hline 순위집합 & 1 & 2 & 3 & 4 & 5 & 6 & 7 & 8 & 9 & 10 & 11 & 12 & 13 & 14 & 15 & 16 & 17 & 18 \\
\hline & $\mathrm{A}$ & $\mathrm{A}$ & $\mathrm{A}$ & $\mathrm{A}$ & $\mathrm{A}$ & $\mathrm{D}$ & $\mathrm{B}$ & $\mathrm{B}$ & $\mathrm{B}$ & $\mathrm{B}$ & $\mathrm{B}$ & $\mathrm{E}$ & $\mathrm{C}$ & $\mathrm{C}$ & $\mathrm{C}$ & $\mathrm{C}$ & $\mathrm{C}$ & $\mathrm{F}$ \\
& $\mathrm{D}$ & $\mathrm{D}$ & $\mathrm{D}$ & $\mathrm{D}$ & $\mathrm{G}$ & $\mathrm{G}$ & $\mathrm{E}$ & $\mathrm{E}$ & $\mathrm{E}$ & $\mathrm{E}$ & $\mathrm{H}$ & $\mathrm{H}$ & $\mathrm{F}$ & $\mathrm{F}$ & $\mathrm{F}$ & $\mathrm{F}$ & $\mathrm{I}$ & $\mathrm{I}$ \\
프로파일 & $\mathrm{G}$ & $\mathrm{G}$ & $\mathrm{G}$ & $\mathrm{J}$ & $\mathrm{J}$ & $\mathrm{J}$ & $\mathrm{H}$ & $\mathrm{H}$ & $\mathrm{H}$ & $\mathrm{K}$ & $\mathrm{K}$ & $\mathrm{K}$ & $\mathrm{I}$ & $\mathrm{I}$ & $\mathrm{I}$ & $\mathrm{L}$ & $\mathrm{L}$ & $\mathrm{L}$ \\
& $\mathrm{J}$ & $\mathrm{J}$ & $\mathrm{M}$ & $\mathrm{M}$ & $\mathrm{M}$ & $\mathrm{M}$ & $\mathrm{K}$ & $\mathrm{K}$ & $\mathrm{N}$ & $\mathrm{N}$ & $\mathrm{N}$ & $\mathrm{N}$ & $\mathrm{L}$ & $\mathrm{L}$ & $\mathrm{O}$ & $\mathrm{O}$ & $\mathrm{O}$ & $\mathrm{O}$ \\
& $\mathrm{M}$ & $\mathrm{P}$ & $\mathrm{P}$ & $\mathrm{P}$ & $\mathrm{P}$ & $\mathrm{P}$ & $\mathrm{N}$ & $\mathrm{Q}$ & $\mathrm{Q}$ & $\mathrm{Q}$ & $\mathrm{Q}$ & $\mathrm{Q}$ & $\mathrm{O}$ & $\mathrm{R}$ & $\mathrm{R}$ & $\mathrm{R}$ & $\mathrm{R}$ & $\mathrm{R}$ \\
\hline
\end{tabular}

로파일이 배치된다. 그런데 통계적 효율성의 관점에서 12 개의 프로파일은 충분하지 않을 수 있으므로 프로파일의 개수를 12 개 이상으로 증가시키려는 경우에는 이 설계가 적합하지 않다. 따라서 프로파일의 개수를 증가시키기 위하여 $\mathrm{BIBD} 10$ 을 세 배로 확장하고 쌍체설계로 전환시켜 순위집합을 구성하는 방 법을 제안한다. 이 방법에 의해 구성한 순위집합은 Table 2.2 와 같은데, 18 개의 프로파일이 18 개의 순 위집합에 5 개씩 동일하게 배치된다. 물론 구성된 순위집합들을 응답자에게 제시하기 위한 조사지에는 순위집합의 순서와 순위집합내의 프로파일들의 순서를 무작위로 재배치해야 한다.

\section{3. 선호도순위의 측정}

$\mathrm{RBCA}$ 를 위한 자료를 얻기 위하여 순위집합들을 응답자들에게 제시하고 각 순위집합에 포함된 프로파 일들에 대한 선호도의 순위를 매기도록 한다. 그리고 각 프로파일에 부여된 순위들의 평균을 기준으로 전체 프로파일들의 순위를 결정한다. 그런데 이 방법을 적용하는 경우에 몇 개의 프로파일이 동일순위 를 갖는 경우가 발생한다. 동일순위를 갖는 프로파일들의 개별순위는 다음과 같은 기준에 따라 조정할 수 있다. (1) 동일순위에 해당하는 프로파일들을 모두 포함하는 순위집합이 한 개인 경우에는, 그 순위집 합 내에서 각 프로파일의 순위를 기준으로 개별순위를 부여한다. (2) 동일순위에 해당하는 프로파일들을 모두 포함하는 순위집합이 두 개 이상인 경우에는, 그 순위집합들에서 측정된 각 프로파일의 평균 순위 를 기준으로 개별순위를 부여한다. (3) 동일순위에 해당하는 프로파일들을 모두 포함하는 순위집합은 없 지만 일부의 프로파일만 포함하는 순위집합이 존재하는 경우에는, 각 프로파일들의 순위를 비교하여 개 별순위를 부여한다. (4) 동일순위에 해당하는 프로파일들 중에서 일부의 프로파일만 포함하는 순위집합 이 존재하지만 프로파일들의 순위를 직접 비교할 수 없는 경우에는, 각 프로파일의 순위의 평균을 바탕 으로 개별순위를 부여한다.

\section{3. 순위기반 컨조인트분석}

\section{1. 컨조인트모형의 추정}

컨조인트분석의 핵심 요소인 부분가치를 추정하기 위해 컨조인트모형을 설정한다. 모형에 교호작용을 포함시키면 그에 따라 프로파일의 개수가 증가되어야 하므로, 교호작용이 모형의 적합성을 향상시킨다 는 증거가 확인된 경우에만 교호작용을 포함시키고 일반적으로 다음과 같은 주효과모형을 설정한다.

$$
y_{i}=\beta_{0}+\sum_{m=1}^{l_{1}-1} \beta_{1 m} x_{1 m_{i}}+\sum_{m=1}^{l_{2}-1} \beta_{2 m} x_{2 m_{i}}+\cdots+\sum_{m=1}^{l_{k}-1} \beta_{k m} x_{k m_{i}}+\epsilon_{i}, \quad i=1,2, \ldots, n .
$$

여기서 $y_{i}$ 는 제품프로파일 $n$ 개에 대한 선호도 순위, $x_{1 m}, \ldots, x_{k m}$ 는 각 속성의 수준들을 지시변수로 표 기한 값, $\beta_{1 m}, \ldots, \beta_{k m}$ 는 각 수준에 대한 계수, $l_{a}$ 는 각 $a$-번째 속성의 수준의 개수, $\epsilon_{i}$ 는 오차이다.

$\mathrm{RBCA}$ 에서는 반응변수가 순위로 측정되기 때문에 모형 (3.1)의 계수를 추정하기 위해서 단조회귀추정 법을 적용한다. 단조회귀추정을 위한 알고리즘으로는 Gebhardt (1970)와 Johnson (1975)이 있는데, 
경사도법을 적용하여 목적함수 (3.2)를 최적화하는 Johnson (1975)의 알고리즘은 다음과 같다.

$$
\begin{aligned}
Q & =\sum_{i, i^{\prime}} d_{i i^{\prime}}\left(\hat{y}_{i}-\hat{y}_{i^{\prime}}\right)^{2} / \sum_{i, i^{\prime}}\left(\hat{y}_{i}-\hat{y}_{i^{\prime}}\right)^{2}, \quad\left(i \neq i^{\prime}\right), \\
d_{i i^{\prime}} & = \begin{cases}1, & \text { if } \operatorname{sign}\left(\hat{y}_{i}-\hat{y}_{i^{\prime}}\right) \neq \operatorname{sign}\left(y_{i}-y_{i^{\prime}}\right), \\
0, & \text { otherwise. }\end{cases}
\end{aligned}
$$

<단계0> 반응변수 관측치 및 설명변수 행렬의 행들을 두 개씩 묶어 모든 가능한 짝 $\left(y_{i}\left|\boldsymbol{x}_{i}^{T}, y_{i^{\prime}}\right| \boldsymbol{x}_{i^{\prime}}^{T}\right)$ 을 만든 후, $\boldsymbol{z}_{j}^{T}=\boldsymbol{x}_{i}^{T}-\boldsymbol{x}_{i^{\prime}}^{T}\left(j=1, \ldots, f ; f={ }_{n} C_{2}\right)$ 을 행으로 갖는 행렬 $Z$ 와 $h_{j}=y_{i}-y_{i^{\prime}}$ 을 원 소로 갖는 벡터 $\boldsymbol{h}$ 를 구성한다. 반복수 $t=0$ 에서 최소자승추정치를 초기치 $\boldsymbol{\beta}^{(0)}$ 로 지정한다.

<단계 $1>\hat{\boldsymbol{y}}^{(t)}=X \boldsymbol{\beta}^{(t)}$ 을 구하고 $s_{j}^{(t)}=\hat{y}_{i}^{(t)}-\hat{y}_{i^{\prime}}^{(t)}$ 을 원소로 갖는 벡터 $\boldsymbol{s}^{(t)}$ 를 구성한다. $\boldsymbol{h}$ 와 $\boldsymbol{s}^{(t)}$ 의 원 소가 같은 부호인 경우에는 $d_{j}^{(t)}=0$ 으로 다른 부호인 경우에는 $d_{j}^{(t)}=1$ 로 정의하고, $d_{j}^{(t)}$ 을 원소로 갖는 벡터 $\boldsymbol{d}^{(t)}$ 와 행렬 $D^{(t)}=\operatorname{diag}\left\{d_{j}^{(t)}\right\}$ 을 생성한다.

$<$ 단계 $2>$ 목적함수 $Q^{(t)}$ 와 경사도 $\boldsymbol{g}^{(t)}$ 를 다음과 같이 계산한다.

$$
Q^{(t)}=\frac{\boldsymbol{s}^{(t) T} D^{(t)} \boldsymbol{s}^{(t)}}{\boldsymbol{s}^{(t) T} \boldsymbol{s}^{(t)}}, \quad r_{j}^{(t)}=d_{j}^{(t)}-Q^{(t)}, \quad R^{(t)}=\operatorname{diag}\left\{r_{j}^{(t)}\right\}, \quad \boldsymbol{g}^{(t)}=\frac{2}{\boldsymbol{s}^{(t) T} \boldsymbol{s}^{(t)}} Z^{T} R^{(t)} \boldsymbol{s}^{(t)} .
$$

<단계 $3>$ 수렴조건: $\left|\boldsymbol{g}^{(t)}\right|_{\infty}<\delta$ (단, $|\cdot|_{\infty}$ 는 Chebyshev-norm, $\delta$ 는 공차)이 충족되면 <단계 $4>$ 로 간 다. 그렇지 않으면, 보폭 $\alpha$ 를 지정하고 $\beta^{(t)}$ 을 다음과 같이 최신화 하고 <단계 $1>$ 로 간다.

$$
\beta^{(t+1)}=\beta^{(t)}-\alpha g^{(t)} .
$$

<단계 $4>\boldsymbol{\beta}^{(t)}$ 를 단조회귀추정치 $\tilde{\beta}$ 로 출력하고 반복과정의 실행을 종료한다.

\section{2. 부분가치와 상대적 중요도}

응답자별로 컨조인트모형 (3.1)의 단조회귀추정치 $\tilde{\boldsymbol{\beta}}^{T}=\left[\tilde{\beta}_{1 m}, \ldots, \tilde{\beta}_{k m}\right]$ 을 구한 후 수준별 부분가치는 식 (3.3)과 같이 계산한다. 즉, $a$ 번째 속성의 $b$ 번째 수준에 대한 부분가치 $u_{a b}$ 는

$$
u_{a b}= \begin{cases}\tilde{\beta}_{a b}, & \text { for } b=1, \ldots, l_{a}-1, \\ -\sum_{b=1}^{l_{a}-1} \tilde{\beta}_{a b}, & \text { for } b=l_{a}\end{cases}
$$

와 같이 구하고, 각 응답자의 부분가치인 $u_{a b}$ 들의 평균을 구하면 전체 응답자에 대한 부분가치 $U_{a b}$ 가 된다. 한편, $a$ 번째 속성의 상대적 중요도 $R I_{a}$ 는 각 수준별 부분가치의 범위 $\left(w_{a}=\max _{b}\left\{U_{a b}\right\}-\right.$ $\left.\min _{b}\left\{U_{a b}\right\}\right)$ 의 상대적 비중 $\left(R I_{a}=100 w_{a} / \sum_{a=1}^{k} w_{a}\right)$ 으로 구한다.

\section{4. 여성용 향수제품에 대한 RBCA}

향수제품은 알코올 등의 용제에 향료를 $20 \sim 30 \%$ 희석한 것인데, 향료는 천연향료와 합성향료로 구분된 다 (Yoh, 2004). 국내 향수시장의 규모는 전체 화장품시장의 $5 \%$ 정도이며 외국제품이 $80 \%$ 정도를 점 하고 있는 것으로 추산된다. 향수시장의 규모가 커짐과 동시에 향수에 대한 여성소비자들의 니즈 역시 더욱 다양해지고 있다. 사치품으로 인식되던 향수는 여성 자신의 개성과 이미지를 나타내는 방편으로 사용되고 있으며, 소비자 층도 20 대와 30 대를 중심으로 확대되고 있는 추세다. Yoh (2004)에 의하면 
Table 4.1. Attributes and levels of perfume-for-women

\begin{tabular}{ccccc}
\hline 속성 & 브랜드 구분 & 용도 & 용량 & 향기 종류 \\
\hline & 해외유명제품 & 기분전환 & $10 \mathrm{ml}$ 이하 & 아쿠아향 \\
수준 & 국내제품 & 방취 & $30-60 \mathrm{ml}$ & 꽃향 \\
& 로드샵제품 & 이미지메이킹 & $61 \mathrm{ml}$ 이상 & 파우더향 \\
& & & 과일향 \\
\hline
\end{tabular}

연령에 따라서 향수의 구매 목적과 장소 그리고 구매 시 고려사항 등이 다르다. 젊은 연령층이 장년층보 다 향기에 대해 민감하고 선물용보다 주로 본인이 사용하기 위해 향수를 구매한다. 특히 20 대 여성들은 향수를 구매하기 전에 제품의 특성을 미리 파악하고 구매하는 경향이 강하다. 본 연구에서는 20 대 여 성들이 사용하는 향수제품에 대한 선호도분석을 실행하였는데, 순위집합에 의한 선호도 측정방법을 채 택한 $\mathrm{RBCA}$ 를 적용하였다. $\mathrm{RBCA}$ 결과를 바탕으로 여성용 향수제품에 대한 소비자의 선호도에 영향을 미치는 주요 속성들의 상대적 중요도를 평가하고 각 수준에 대한 부분가치를 추정함으로써 다양한 마케 팅 전략의 수립에 활용할 수 있도록 하였다.

\section{1. 제품속성 및 수준의 결정}

자료를 수집하기에 앞서 여성용 향수제품을 구성하는 속성과 수준을 Table 4.1과 같이 선정하였다. 소 비자들이 중요시 하는 속성을 파악하고 각 속성의 수준을 구체적으로 결정하기 위하여 관련 문헌을 참 고하고 표적집단면접조사를 실시하였다. 속성들은 상호독립적이면서 제품의 특성을 잘 나타내는 것들 로 선정하였는데, 향수의 브랜드, 용도, 용량, 향기 종류를 선정하였다. 한편 수준들은 중첩되지 않으면 서 포괄적인 것을 선정하였으며 수준의 개수는 모든 속성에 걸쳐 비슷한 개수가 되도록 선정하였다. 수 준의 개수가 너무 많으면 응답자가 선호도를 정확히 평가하기 어려우므로 4 개 이하로 제한하였다. $\mathrm{Yi}$ 등 (2000)에 의하면 우리나라 여성들은 국내제품보다 외국제품을 선호하지만 최근에는 국내브랜드 향수 시장이 확장되고 있다고 한다. 향수의 브랜드는 종류가 많기 때문에 개별 브랜드를 선정하지 않고 브랜 드를 넓게 구분하여 외국유명제품(Lanvin, Chanel, Dior 등), 국내제품(Lolita Lempicka, Espoir 등), 그리고 20 대 여성들이 많이 구매하는 로드샵제품(Missha, Thefaceshop, Innisfree, Tonymoly 등)을 선 정하였다. 젊은 여성들은 자신의 이미지를 나타내거나 스스로 만족감을 얻기 위하여 향수를 사용하는 것으로 파악되었으므로 향수의 용도는 기분전환, 방취, 이미지메이킹으로 결정하였다. 용량의 수준들을 선정하기 위하여 사용편의성과 경제성 그리고 사용기간이 길어지면 효능이 저하된다는 우려 등을 고려 하였으며, 사용하기에 편리한 $10 \mathrm{ml}$ 이하의 소용량, 시판중인 대다수 제품들의 용량인 $30 \mathrm{ml} 60 \mathrm{ml}$, 그 리고 $61 \mathrm{ml}$ 이상의 대용량으로 구분하였다. 향기 종류로는 아쿠아향, 과일향(사과, 파인애플, 산딸기, 복숭아 등), 파우더향, 꽃향(히야신스, 백합, 프리지어, 재스민, 장미 등)이 많이 사용된다. 그런데 과일 향과 꽃향의 종류가 너무 다양해서 구체적인 향을 수준으로 선정하지 않았다.

\section{2. 순위집합의 구성}

선정된 속성과 수준들을 바탕으로 요인설계에 의해 108 개의 제품프로파일을 구성하였다. 그런데 전체 프로파일을 포함하는 순위집합을 구성하면 집합의 개수가 너무 많아져서 응답자가 선호도를 평가하는 작업에 부담을 느껴 선호도 측정을 정확하게 하기 어렵다. 따라서 Kuhfeld와 Tobias (2005)와 Voelkel (2005)이 제안한 D-최적화 기준을 적용하여 D-효율성이 0.9736 인 20 개의 프로파일을 Table 4.2 와 같 이 선정하였다. 선정된 20 개의 프로파일들은 응답자의 부담과 응답효율성을 고려하여 10 개의 순위집합 에 각각 6 개씩 배치하기로 결정하였다. BIBD4를 두배 확장하여 변환한 순위집합(Table 4.3)을 구성하 
Table 4.2. Profiles of perfume-for-women selected by D-optimization criteria

\begin{tabular}{ccccc}
\hline 프로파일 & 브랜드 구분 & 용도 & 용량 $(\mathrm{ml})$ & 향기 종류 \\
\hline 1 & 로드샵제품 & 이미지메이킹 & 61 이상 & 꽃향 \\
2 & 로드샵제품 & 기분전환 & 10 이하 & 꽃향 \\
3 & 해외유명제품 & 기분전환 & $30-60$ & 아쿠아향 \\
$\vdots$ & $\vdots$ & $\vdots$ & $\vdots$ & $\vdots$ \\
18 & 로드샵제품 & 이미지메이킹 & 10 이하 & 아쿠아향 \\
19 & 국내제품 & 이미지메이킹 & $30-60$ & 과일향 \\
20 & 국내제품 & 방취 & 61 이상 & 아쿠아향 \\
\hline
\end{tabular}

Table 4.3. Ranking sets constructed by expanding BIBD4 doubly and transforming to dual design

\begin{tabular}{ccccccccccccc}
\hline 순위집합 & 1 & 2 & 3 & 4 & 5 & 6 & 7 & 8 & 9 & 10 \\
\hline & 1 & 1 & 1 & 5 & 3 & 2 & 2 & 2 & 6 & 4 \\
프로파일 & 3 & 3 & 7 & 7 & 5 & 4 & 4 & 8 & 8 & 6 \\
& 5 & 7 & 9 & 9 & 9 & 6 & 8 & 10 & 10 & 10 \\
& 11 & 11 & 13 & 11 & 15 & 12 & 12 & 14 & 12 & 16 \\
& 13 & 17 & 15 & 13 & 17 & 14 & 18 & 16 & 14 & 18 \\
& 15 & 19 & 17 & 19 & 19 & 16 & 20 & 18 & 20 & 20 \\
\hline
\end{tabular}

Table 4.4. Examples of ranking sets for RBCA of perfume-for-women

\begin{tabular}{|c|c|c|c|c|c|c|c|}
\hline 순위집합 & 속성 & 프로파일1 & 프로파일2 & 프로파일3 & 프로파일4 & 프로파일5 & 프로파일6 \\
\hline \multirow{4}{*}{$\sharp 1$} & $\begin{array}{c}\text { [브랜드구분] } \\
\text { [용도] }\end{array}$ & $\begin{array}{c}\text { 해외유명제품 } \\
\text { 기분전환 }\end{array}$ & $\begin{array}{c}\text { 로드샵제품 } \\
\text { 이미지메이킹 }\end{array}$ & $\begin{array}{c}\text { 해외유명제품 } \\
\text { 기분전환 }\end{array}$ & $\begin{array}{l}\text { 해외유명제품 } \\
\text { 이미지메이킹 }\end{array}$ & $\begin{array}{c}\text { 해외유명제품 } \\
\text { 방취 }\end{array}$ & $\begin{array}{c}\text { 해외유명제품 } \\
\text { 방취 }\end{array}$ \\
\hline & [용량 $(\mathrm{ml})]$ & $30-60$ & 61 이상 & 61 이상 & $30-60$ & 10 이하 & 10 이하 \\
\hline & [향기종류] & 아쿠아향 & 꽃향 & 과일향 & 파우더향 & 과일향 & 꽃향 \\
\hline & 순위 & $(\quad)$ & $(\quad)$ & $(\quad)$ & $(\quad)$ & $(\quad)$ & $(\quad)$ \\
\hline 순위집합 & 속성 & 프로파일1 & 프로파일 2 & 프로파일3 & 프로파일4 & 프로파일5 & 프로파일6 \\
\hline \multirow{4}{*}{$\sharp 10$} & $\begin{array}{c}\text { [브랜드구분] } \\
\text { [용도] }\end{array}$ & $\begin{array}{c}\text { 로드샵제품 } \\
\text { 방취 }\end{array}$ & $\begin{array}{c}\text { 국내제품 } \\
\text { 방취 }\end{array}$ & $\begin{array}{c}\text { 로드샵제품 } \\
\text { 이미지메이킹 }\end{array}$ & $\begin{array}{l}\text { 해외유명제품 } \\
\text { 이미지메이킹 }\end{array}$ & $\begin{array}{c}\text { 로드샵제품 } \\
\text { 방취 }\end{array}$ & $\begin{array}{l}\text { 국내제품 } \\
\text { 기분전환 }\end{array}$ \\
\hline & [용량 $(\mathrm{ml})]$ & $30-60$ & 61 이상 & 10 이하 & 61 이상 & $30-60$ & $30-60$ \\
\hline & [향기종류] & 과일향 & 아쿠아향 & 아쿠아향 & 아쿠아향 & 아쿠아향 & 꽃향 \\
\hline & 순위 & $(\quad)$ & $(\quad)$ & $(\quad)$ & $(\quad)$ & $(\quad)$ & $(\quad)$ \\
\hline
\end{tabular}

고 프로파일의 순서를 임의로 배치하여 Table 4.4 와 같은 컨조인트 조사표를 작성하였다.

\section{3. 컨조인트조사}

젊은 연령층의 유동인구가 많은 서울지역에서 20 대 여성 190 명을 편의추출하고 직접면접법으로 컨조 인트조사를 실시하였다. 응답자들의 특성을 살펴보면 20대전반(20세 24 세)이 125 명 $65.8 \%), 20$ 대후 반(25 29세)이 65 명(34.2\%)이었다. 선호도 측정도구로는 조사지를 사용하였는데 순위집합들과 함께 연령, 소득여부, 연간 향수 구입횟수에 대한 질문을 포함시켰다. 각 순위집합에 배치된 6 개의 프로파일 에 대해 응답자가 선호하는 순위를 매기도록 하였으며, 각 프로파일에 부여된 순위들의 평균을 구하여 전체 프로파일의 순위를 얻었다. 한편, 동일순위가 발생한 경우에는 제 2 장 3 절에 소개된 기준에 따라 개별순위로 조정하였다. 응답자별로 변환회귀를 실행하여 구한 $R^{2}$ 의 평균이 동일순위를 조정하기 전 
Table 4.5. Estimates of part-worth and relative importance in total and segmented markets

\begin{tabular}{|c|c|c|c|c|c|c|c|}
\hline \multirow{2}{*}{ 속성 } & \multirow{2}{*}{ 수준 } & \multicolumn{3}{|c|}{ 부분가치 } & \multicolumn{3}{|c|}{ 상대적 중요도 } \\
\hline & & 전체 & 20 대전반 & 20대후반 & 전체 & 20대전반 & 20 대후반 \\
\hline \multirow{3}{*}{ 브랜드 구분 } & 해외유명제품 & 26.17 & 22.68 & 32.65 & \multirow{3}{*}{29.74} & \multirow{3}{*}{23.36} & \multirow{3}{*}{37.49} \\
\hline & 국내제품 & -8.87 & -8.16 & -10.18 & & & \\
\hline & 로드샵제품 & -17.30 & -14.52 & -22.47 & & & \\
\hline \multirow{3}{*}{ 용도 } & 기분전환 & -4.39 & -7.70 & 1.77 & \multirow{3}{*}{8.00} & \multirow{3}{*}{11.28} & \multirow{3}{*}{3.71} \\
\hline & 방취 & -2.93 & -2.56 & -3.61 & & & \\
\hline & 이미지메이킹 & 7.31 & 10.26 & 1.85 & & & \\
\hline \multirow{3}{*}{ 용량 } & $10 \mathrm{ml}$ 이하 & -8.24 & -14.50 & 3.38 & \multirow{3}{*}{12.31} & \multirow{3}{*}{14.14} & \multirow{3}{*}{19.94} \\
\hline & $30-60 \mathrm{ml}$ & 9.75 & 8.02 & 12.97 & & & \\
\hline & $60 \mathrm{ml}$ 이상 & -1.51 & 6.48 & -16.35 & & & \\
\hline \multirow{4}{*}{ 향기 종류 } & 아쿠아향 & 38.88 & 45.95 & 25.78 & \multirow{4}{*}{49.952} & \multirow{4}{*}{51.22} & \multirow{4}{*}{38.86} \\
\hline & 꽃향 & 4.03 & 2.27 & 7.27 & & & \\
\hline & 파우더향 & -8.78 & -12.60 & -1.69 & & & \\
\hline & 과일향 & -34.13 & -35.62 & -31.36 & & & \\
\hline
\end{tabular}

0.8336 에서 조정 후 0.8643 으로 증가되었다. 이 결과는 동일순위를 조정함으로써 모형의 적합성을 향상 시킬 수 있음을 보여준다.

\section{4. $\mathrm{RBCA}$ 에 의한 선호도분석}

컨조인트분석에 부적합하다고 판단된 조사지(변환회귀의 $R^{2}$ 가 0.6 미만인 조사지)를 제외하고 177 명의 선호도 순위를 대상으로 $\mathrm{RBCA}$ 를 실행하였다. 그리고 예비분석 결과로부터 연령별로 소비자들의 구매 행동이 매우 다르다는 사실을 발견하였으므로 연령별 세분시장에서의 RBCA를 실행하였다.

\section{(1) 전체시장에서의 $\mathrm{RBCA}$}

$\mathrm{RBCA}$ 결과(Table 4.5)에 의하면 20대 여성 소비자들이 향수를 구입할 때 가장 중요시하는 속성은 향 기 종류이며 다음은 브랜드, 용량, 용도 순서인 것으로 분석되었다. 브랜드보다 향기 종류에 더 민감하 고 용도는 주로 이미지메이킹용으로 생각하는 것으로 분석되었다. 부분가치를 살펴보면 향기 종류 중에 서 아쿠아향을 가장 선호하고 과일향을 선호하지 않았다. 브랜드에서는 해외유명제품을 가장 선호하고 로드샵제품을 선호하지 않았다. 용량은 $30 \sim 60 \mathrm{ml}$ 인 중간 크기를 가장 선호하고 $10 \mathrm{ml}$ 이하의 소용량을 선호하지 않는 것으로 나타났다. 따라서 아쿠아향으로 만든 해외유명제품중에서 $30 \sim 60 \mathrm{ml}$ 크기의 향수 를 여성 소비자들은 가장 선호하며 주로 이미지메이킹용으로 구매하는 것으로 분석되었다.

\section{(2) 세분시장에서의 $\mathrm{RBCA}$}

소비자의 수입이 있는지 여부가 향수 구매행동에 영향을 미친다고 판단하여, 주로 대학생들인 20 대전 반과 대학원생이나 직장인이 주로 해당되는 20 대후반으로 시장을 세분하였다. 분석대상자들은 20 대전 반이 115 명 $(65 \%), 20$ 대후반이 62 명 $(35 \%)$ 이었다. 세분시장에서의 RBCA 결과(Table 4.5$)$ 에 의하면, 20 대전반과 후반 모두 향기 종류를 가장 중요시 하고 다음으로 브랜드, 용량, 용도의 순서로 중요시 하 였다. 그러나 연령층별로 상대적 중요도의 크기는 확연히 다르다는 것을 알 수 있었다. 20 대전반의 소 비자들은 후반보다 향기 종류를 더 중요시하는 특징을 보였다. 반면에 20대후반에는 수입이 있는 직장 인들이 많기 때문에 전반보다 브랜드에 관심이 더 많은 것으로 분석되었다. 그리고 20 대전반은 후반에 
비하여 향수의 용도를 더 중요시 하였으나, 20 대후반은 전반에 비하여 용량을 중요시 하였다. 한편, 부 분가치를 살펴보면 연령층과 관계없이 아쿠아향을 가장 선호하고 과일향을 선호하지 않았으며 20 대전 반이 향기 종류에 더 민감한 것으로 나타났다. 브랜드는 해외유명제품을 가장 선호하고 로드샵제품을 선호하지 않았으며 20 대후반이 브랜드에 더 민감한 것으로 분석되었다. 향수의 용도는 연령 구분 없이 이미지메이킹용을 선호하며 20 대전반보다 후반이 기분전환용을 선호하는 것으로 나타났다. 20 대전반은 $10 \mathrm{ml}$ 이하의 소용량을 선호하지 않았으나 후반은 $60 \mathrm{ml}$ 이상의 대용량을 선호하지 않았다. 이 결과는 20 대전반이 경제성에 비중을 더 두는 반면에, 후반은 휴대편의성에 더 관심을 가지고 있기 때문인 것으 로 해석된다. 이와 같이 20 대전반과 후반 소비자들의 선호도분석에서 몇 가지 현저한 차이가 발견되었 으므로 연령별 세분시장의 특성과 소비자의 니즈를 고려하여 마케팅전략을 수립할 필요가 있다.

\section{5. 결론}

순위기반 컨조인트분석을 위한 선호도 측정과정에서 제품프로파일들에 대한 선호도를 순위로 평가해야 하는 응답자의 부담을 줄여주고, 정확한 선호도 평가를 할 수 있도록 하기 위하여 새로운 측정방법을 제 안하였다. 이 측정방법은 몇 개의 순위집합을 구성하여 응답자에게 제시하고 각 순위집합에 포함된 소 수의 프로파일에 대해서만 순위를 매기게 하는 것이므로 응답효율성이 상당히 제고될 것으로 기대된다. 순위집합들은 균형불완비블럭설계들을 활용하여 체계적으로 구성할 수 있는데, 프로파일의 개수가 많은 상황도 수용할 수 있도록 기본 설계를 두 배 또는 세 배로 확장하고 쌍체설계로 전환하여 순위집합을 구 성하는 방법을 개발하였다. 이 방법을 적용하여 순위집합을 구성하면, 모든 순위집합에 동일한 개수의 프로파일이 포함되고 각 프로파일은 응답자에게 동일한 횟수로 제시된다. 특히, 두 개의 프로파일이 함 께 포함된 순위집합의 개수가 같게 구성되므로, 동일순위를 조정하기 위한 기준으로 활용할 수 있다는 장점을 갖는다. 또한 이 측정방법은 Vermeulen 등 (2010)이 제안한 최선-최악 선택기반 컨조인트분석 에도 적용될 수 있다는 특성을 갖는다. 한편, 여성용 향수제품의 선호도 분석을 위하여 새로운 측정방법 을 적용한 컨조인트분석을 실행하였다. 그런데 새로운 측정방법과 기존의 방법들을 동일한 응답자들에 게 적용한 컨조인트조사를 실행할 수 없었기 때문에 응답자가 느끼는 부담의 크기나 응답에 소요되는 시 간을 정량적으로 비교할 수 없는 한계가 있었음을 밝힌다.

\section{References}

Chen, Y. H., Hsu, I. C. and Lin, C. C. (2010). Website attributes that increase consumer purchase intention: A conjoint analysis, Journal of Business Research, 63, 1007-1014.

Choi, S. (2006). Developing fashion products of casual brand with conjoint analysis, Family and Environment Research, 44, 105-115.

Choi, W. S., Seo, K. H. and Lee, S. B. (2012). A study on the development of HMR products of Korean foods using conjoint analysis, The Korean Journal of Culinary Research, 18, 156-167.

Gebhardt, F. (1970). An algorithm for monotone regression with one or more independent variables, Biometrika, 57, 263-271.

Hong, J. S., Jeon, J. Y., and Kim, Y. S. (2012). Study on consumers' restaurant selection criteria by using conjoint analysis, Journal of East Asian Society of Dietary Life, 22, 315-321.

Jin, B., Park, J. Y. and Ryu, J. S. (2010). Comparison of Chinese and Indian consumers' evaluative criteria when selecting denim jeans: A conjoint analysis, Journal of Fashion Marketing and Management, 14, $180-194$.

Jo, M. N. (2010). Conjoint analysis of restaurant attributes on customer intentions to choose restaurant, The Korean Journal of Culinary Research, 16, 254-268.

Johnson, R. M. (1975). A simple method for pairwise monotone regression, Psychometrika, 40, $163-168$. 
Jung, U. (2012). Conjoint analysis on the academia-industrial cooperative research project attributes for culture technology research, Management Science and Financial Engineering, 29, 13-21.

Kim, B. Y. (2005). Conjoint analysis for the development of new cellular phone, Journal of Korean Society for Quality Management, 33, 103-110.

Kim, B. Y. (2012). New design of choice sets for choice-based conjoint analysis, The Korean Journal of Applied Statistics, 25, 847-857.

Kim, H. R., Lee, K. D., Hwang, Y. H. and Lee, M. (2005). Developing logo icon design based on brand concept: An exploratory study with conjoint analysis, Journal of Korean Society of Design Science, 18, 173-183.

Kim, K. J. and Park, K. Y. (2007). Research on development concept of Korean restaurant through conjoint analysis focused on breakfast food service market, Journal of Tourism Sciences, 31, 319-336.

Kuhfeld, W. F. and Tobias, R. D. (2005). Large factorial designs for product engineering and marketing research applications, Technometrics, 47, 132-141.

Kutner, M. H., Nachtsheim, C. J., Neter, J., and Li, W. (2005). Applied Linear Statistical Models, McGraw Hill.

Lee, E. Y., Park, Y. W. and Lee, S. B. (2010). An exploratory study on selection attributes of food in the cultural tourism festival through conjoint analysis, The Korean Journal of Culinary Research, 16, 94-113.

Lee, J., Ahn, J., Lee, J. D. and Shin, H. (2004). Demand analysis of the home ubiquitous network services using conjoint method, Journal of Korea Technology Innovation Society, 7, 89-110.

Lee, S., Shin, Y. and Park, Y. (2005). A study on designing mobile phone in consideration of elder people's optical characteristics and preferences: Using conjoint analysis and response surface method, Journal of Korea Lasbiburte of Information and Telecom, 4, 23-29.

Min, W., Kwon, S. and Jang, S. (2000). The study on the buying pattern in e-business by conjoint analysis, Journal of the Korean Data and Information Science Society, 11, 347-357.

Ong, F. S., Kitchen, P. F. and Chew, S. S. (2010). Marketing a consumer durable brand in Malaysia: A conjoint analysis and market simulation, Journal of Consumer Marketing, 27, 507-515.

Park, H., Park, H., Baek, M. and Park, J. (2008). Use of conjoint analysis to test consumer preferences on database service quality for knowledge information, Journal of Korea Society of IT Services, 7, 13-23.

Park, R. J. and Lee, D. H. (2011). Information security risk: Application of the conjoint analysis, Journal of Korean Data \& Information Science Society, 22, 207-215.

Sayadi, S., Roa, M. C. G. and Requena, J. C. (2005). Ranking versus scale rating in conjoint analysis: Evaluating landscapes in mountainous regions in southeastern Spain, Ecological Economics, 55, 539550

Shin, S. Y., Chang, H. J., Yang, I. S., Chung, L. I. and Lee, H. Y. (2004). Assessing relative importance of Korean traditional food tour program attributes based on conjoint analysis, Korean Journal of Community Nutrition, 9, 654-662.

Shin, Y. J., Kim, B. Y. and Hyun, Y. J. (2007). Conjoint analysis for the effects of cigarette warning label and packaging on intention to quit, Journal of Health and Social Affairs, 27, 27-51.

Vermeulen, B., Goos, P. and Vandebroek, M. (2010). Obtaining more information from conjoint experiments by best-worst choices, Computational Statistics \& Data Analysis, 54, 1426-1433.

Voelkel, J. G. (2005). The efficiencies of fractional factorial designs, Technometrics, 47, 488-494.

Yi, K. H., Ryou, E. J. and Kim, K. H. (2000). Perfume consumption behavior of female college students based on the frequency of perfume usage, Journal of the Korean Society of Costume, 50, 143-153.

Yoh, E. (2004). Exploratory research on perfume consumption and purchase behaviors, Family and Environment Research, 42, 177-193.

Yoon, H. R. and Cho, M. S. (2009). Preferences of food service types for the elderly patients at the long-term care facilities through conjoint analysis, The Korean Journal of Food and Nutrition, 22, 141-149. 


\title{
순위기반 컨조인트분석에서 선호도측정을 위한 새로운 방법
}

\author{
김부용 ${ }^{a, 1}$ \\ ${ }^{a}$ 숙명여자대학교 통계학과
}

(2013년 10월 20일 접수, 2013년 12월 2일 수정, 2013년 12월 2일 채택)

\section{요 약}

순위기반 컨조인트분석은 마케팅조사를 비롯한 다양한 분야에서 널리 활용되고 있다. 이 분석기법은 다른 기법들에 비하여 몇 가지 장점을 가지고 있는 반면에, 응답자들이 다수의 제품프로파일들에 대한 선호도 순위를 정확하게 평 가하기 어렵다는 한계를 가지고 있다. 본 논문에서는 응답효율성을 향상시키기 위하여 순위집합 개념을 도입한 새로 운 선호도 측정방법을 제안한다. 응답자에게 순위집합들에 포함된 소수의 프로파일들에 대한 선호도를 순위로 평가 하게 한 후 평가결과를 종합하여 프로파일 전체에 대한 순위를 얻는 방법이다. 이 방법에 의하면 응답자가 프로파일 들에 대한 선호도 순위를 매기는 작업을 용이하게 할 수 있고 선호도 순위를 효율적으로 평가할 수 있다. 한편, 다 수의 프로파일을 수용할 수 있는 순위집합을 체계적으로 구성하기 위하여 균형불완비블록설계를 확장하여 쌍체설계 로 전환시키는 방법을 개발하였다. 제안된 측정방법을 채택한 순위기반 컨조인트분석을 여성용 향수제품에 대한 소 비자 선호도분석에 실제로 적용하였다.

주요용어: 순위기반 컨조인트분석, 순위집합, 군형불완비블록설계, 여성용향수. 